\title{
Further evidence for sublexical components in implicit memory for novel words
}

\author{
JENNIFER DORFMAN \\ Rush-Presbyterian-St. Luke's Medical Center, Chicago, Illinois
}

\begin{abstract}
This study provides further evidence for the notion, proposed by Dorfman (1994), that activation of sublexical components plays an important role in implicit memory for novel words. Priming in an identification task was observed consistently when nonwords were formed out of morphemes; weaker, more variable effects were observed when nonwords were composed of syllables or pseudosyllables. Priming was insensitive to changes in the surface features (type case) of the stimuli and was disrupted by rearrangement of the stimulus components. Results are interpreted in terms of the activation and integration of preexisting sublexical representations and as evidence against the role of newly established episodic or perceptual representations. It is concluded that findings of priming for novel information should not be taken as evidence against an activation view.
\end{abstract}

Implicit memory is expressed when a prior event facilitates performance on a task in which conscious recollection is not required (Schacter, 1987; see also Graf \& Schacter, 1985). In one commonly studied subtype of implicit memory, priming, this facilitation may be revealed as greater accuracy or reduced latency in identifying words or pictures from brief displays, generating items in response to partial cues, or making judgments or decisions pertaining to some dimension of a stimulus. A large body of literature has developed indicating that priming effects in implicit memory, in both normal subjects and neurologically impaired individuals, are dissociable from performance on traditional explicit memory measures, such as recall or recognition (for reviews, see Richardson-Klavehn \& Bjork, 1988; Roediger \& McDermott, 1993; Schacter, 1987) ${ }^{1}$

Whereas many early demonstrations of priming used stimuli that were familiar to subjects preexperimentally, it is now widely recognized that implicit memory can occur for novel materials - nonwords, pairs of unrelated words, unfamiliar objects, and so on (see, e.g., Bowers, 1994; Graf \& Schacter, 1985; Jacoby, Woloshyn, \& Kelley, 1989; Johnson, Kim, \& Risse, 1985; Musen \& Squire,

Portions of this research were presented at the 34th Annual Meeting of the Psychonomic Society, Washington, D.C., November 1993. This research was supported by National Institute of Mental Health (NIMH) postdoctoral fellowship MH10042 to J.D. and by NIMH Grant MH35856 to John Kihlstrom. I extend special thanks to John Kihlstrom for use of his laboratory and for many invaluable discussions. I also thank Ken Forster for his helpful suggestions and Lara Mitchell and Jennifer Marecek for assistance in data collection and analysis. I am grateful to Jeff Bowers, George Mandler, Jay Rueckl, and two anonymous reviewers for their comments on an earlier version of the manuscript, and to Donald Dorfman for statistical advice. Correspondence concerning this article should be addressed to J. Dorfman, Section of Cognitive Neuroscience, Rush-Presbyterian-St. Luke's Medical Center, 1645 W. Jackson, Suite 450, Chicago, IL 60612 (e-mail: jdorfman@rush.edu).

-Accepted by previous associate editor Kathryn T. Spoehr
1991; Rueck1, 1990; Schacter, Cooper, \& Delaney, 1990; Schacter \& Graf, 1986). Implicit memory for novel material is theoretically important, because it seems to challenge the activation view of priming. According to this view, priming reflects the automatic activation of abstract preexisting memory traces, schemas, or logogens (see, e.g., Diamond \& Rozin, 1984; Graf \& Mandler, 1984; Morton, 1979). Because novel stimuli do not have preexisting representations to activate, priming presumably cannot be based on activation processes. Thus, the phenomenon of implicit memory for novel information is generally taken as strong support for the view that priming must rely on the establishment of new, highly specific representations in episodic memory (see, e.g., Jacoby, 1983; Roediger \& Blaxton, 1987) or a domain-specific perceptual representation system (see, e.g., Schacter, 1990; Tulving \& Schacter, 1990). This account of priming may be called the new representations view.

In Dorfman (1994), I detailed the pitfalls of making theoretical conclusions on the basis of findings of priming of novel information. In brief, priming of an ostensibly novel stimulus may be based on activation of familiar components of that stimulus that are already represented in memory. By components, I mean units that are psychologically functional - that is, features or characteristics of a stimulus that are perceptually salient and that are used in multiple contexts. For example, morphemes may be construed as components, to the extent that they seem to play a role in the perception, recognition, and production of words (see, e.g., Caramazza, Laudanna, \& Romani, 1988; Fowler, Napps, \& Feldman, 1985; Garrett, 1980; Murrell \& Morton, 1974; Rapp, 1992; Stanners, Neiser, \& Painton, 1979; Taft \& Forster, 1975). Random sequences of letters, by contrast, may not be characterized as components, because they are neither perceived as units nor used in a functional context.

Certainly, componential information of this kind plays an important role at many levels within the cognitive sys- 
tem. For instance, letter perception is accomplished by extracting elementary features such as lines, curves, and angles. Word perception seems to involve extraction of morphological information and, perhaps, information about syllable or subsyllable structure as well (see, e.g., Bowey, 1990; Forster \& Taft, 1994; Klapp, 1971; Rapp, 1992; Santa, Santa, \& Smith, 1977; Spoehr \& Smith, 1973; Taft \& Forster, 1976; Treiman \& Chafetz, 1987). Shape recognition depends on primitive components, such as edges, contours, and vertices. In the three-dimensional case, these elementary units form volumetric components or geons, such as cylinders, bricks, and spheres, which seem to play a vital role in object recognition (see, e.g., Biederman, 1987; Hochberg \& Peterson, 1987). Importantly, there is evidence that componential information contributes to the perception and recognition of novel stimuli. For example, Taft and Forster (1975) showed that nonwords containing stem morphemes (e.g., DEJUVENATE) take longer to reject in lexical decision than nonwords containing pseudostem morphemes (e.g., DEPERTOIRE). Given these kinds of findings and the general dependence of priming phenomena on perceptual processes, it is reasonable to suppose that one might see similar effects in implicit memory.

In keeping with this notion, I demonstrated in a previous series of experiments that priming of novel words depends critically on the underlying componential structure of a stimulus (Dorfman, 1994). The subjects studied nonwords composed of novel combinations of morphemes (e.g., GENVIVE), syllables (e.g., GARBRID), or pseudosyllables (syllable-like letter sequences that do not form syllables in any English word; e.g., ERKTOFE). They then completed an implicit word judgment task in which they were given a pair of nonwords, one previously presented and one new (e.g., GENVIVE-GENCULE), and were asked to select which was a better English word. The basic finding was a mere exposure effect in which the subjects were biased to select previously exposed items when those items were formed out of familiar sublexical components but not when they were formed out of unfamiliar pseudosyllabic sequences. This priming effect was reduced when the components composing a nonword were rearranged, indicating that both components and the relations between them were important for priming.

These results were interpreted in terms of Mandler's $(1979,1980,1989)$ dual-process model of memory, which attributes implicit memory effects to the activation and integration of preexisting memory representations. (Explicit memory-e.g., recall-is based primarily on a process of interevent elaboration, which, in conjunction with activation-integration, forms the basis of recognition.) According to this view, priming is based on distributed representations built up from experience with incoming patterns of feature co-occurrence. In the case of a typical familiar stimulus with a unitized representation (e.g., a word or object), initial processing activates the constituent features of the representation and strengthens or integrates the relations among those features. This increases the likelihood of accessing that representation when the stimulus, or portions of it, are reencountered on a test of implicit memory.

More relevant here, presentation of a novel stimulus (e.g., a nonword or novel object) activates componential representations corresponding to whatever elements are parsed during initial perception (e.g., sublexical components or object parts). Associative links are established among these components, producing an integrated representation of the perceived stimulus - that is, a representation that preserves the componential makeup of the stimulus as well as its holistic structure. Mandler (1979, 1989) has called such representations "coordinate," or relational, structures - structures in which two or more functional units are brought together to produce a single functional unit. This view of representation is similar to Hayes-Roth's (1977) knowledge assembly theory, a Hebbian-type framework in which all learning progresses through the unitization of elementary components or features into integrated wholes. It is also very similar to Bower's (1996) recent reactivation theory of implicit memory in which novel stimuli are represented as associations between familiar sensory units-in-position and a global configural representation.

One can view the results of Dorfman (1994), then, as indicating an advantage in priming for novel words that make active, and amenable to integration, preexisting sublexical components. Morphemic items such as GENVIVE or syllabic items such as GARBRID may be encoded by activating and linking their component elements. This is not true of pseudosyllabic items such as ERKTOFE: The largest units that such items can activate are at the level of the letter or letter cluster; integration of these multiple components may be difficult to accomplish due to limits in the number of elements that can be processed simultaneously (cf. Mandler, 1979). Multiple stimulus presentations or more extensive processing activities may be required to establish an integrated memory trace that can support priming of these items.

In general, any activation view with a hierarchical representational scheme can account for findings of priming of novel information. Thus, nonword priming may be attributed not only to the activation and integration of sublexical representations, but to interactive activation of letter and word nodes-as in MAVE activating SAVE, MOVE, and MALE, which in turn activate M, A, V, and E (McClelland \& Rumelhart, 1981; see also Rueckl, 1990). Similarly, novel object priming may be based on the activation of familiar object parts and their relations (Biederman \& Cooper, 1991) or on the interactive activation of visual features (edges, vertices, etc.), object parts, and object models (Biederman, 1987).

Consistent with an activation approach, previous demonstrations of nonword priming have generally used pronounceable, orthographically legal stimuli (e.g., MALK; Feustel, Shiffrin, \& Salasoo, 1983; Musen \& Squire, 1991; Rueckl, 1990). Such stimuli are likely to activate preexisting linguistic knowledge. Moreover, several studies have 
documented that priming is reduced or absent when nonwords violate the rules of English (e.g., SKHRA; Challis, Jaciw, \& Pivetta, 1992; Rugg \& Nagy, 1987; Scarborough, Cortese, \& Scarborough, 1977; Schacter, Rapscak, Rubens, Tharan, \& Laguna, 1990; but see Bowers, 1994; Keane, Gabrieli, Noland, \& McNealy, 1995). ${ }^{2}$ A study using positron emission tomography demonstrated that the same part of the brain (left extrastriate cortex) is implicated in the processing of words and legal nonwords but not illegal nonwords (Petersen, Fox, Snyder, \& Raichle, 1990). A role for prior semantic knowledge has been demonstrated in a study by Cermak, Verfaellie, Milberg, Letourneau, and Blackford (1991), who found that priming is stronger for nonwords that are homophones of real words (e.g., PHAIRE) than for nonhomophonous nonwords.

The purpose of the present study was to provide further evidence for the role of sublexical components in implicit memory for novel words and for an activation theory of priming. There were two primary aims of the study: (1) to extend the generality of the effects observed in Dorfman (1994) by using a different implicit memory paradigm, and (2) to investigate in further detail the conditions that may affect priming of novel words. A word identification task was used to assess priming. In this task, the subjects view a briefly exposed stimulus, followed by a pattern mask. Priming is indicated by an increased accuracy in identifying the stimulus as a function of prior exposure. There are two primary reasons for using this task. First, it is a well-established implicit memory paradigm, and it is important to show that the effects of Dorfman (1994) can be reproduced in such a task. Previous studies have shown that nonword priming occurs consistently in this task, both in normal subjects and in amnesic patients (see, e.g., Bowers, 1994; Cermak et al., 1991; Feustel et al., 1983; Haist, Musen, \& Squire, 1991; Rueckl, 1990; Salasoo, Shiffrin, \& Feustel, 1985). ${ }^{3}$ More critically, the effects observed in my previous study may have reflected response biases idiosyncratic to the word judgment task: Priming may have occurred minimally for pseudosyllabic items because the subjects were unable to judge which of two poor instances of an English word was the better one. Such differential responding is unlikely to occur in the word identification task.

I expected to obtain the same pattern of results I observed previously - that is, stronger priming for morphemic and syllabic than for pseudosyllabic items. Such results would provide further evidence for the activationintegration view. An outcome indicating equivalent performance regardless of the componential structure of a stimulus, however, might suggest that priming relies on a newly established episodic or perceptual representation, independent of prior knowledge. Finally, it is possible that an advantage in priming may be observed for morphemic as compared with either syllabic or pseudosyllabic items. Syllabic effects occur inconsistently in word recognition (see, e.g., Eriksen, Pollack, \& Montague, 1970; Prinzmetal, Treiman, \& Rho, 1986; Rapp, 1992; Spoehr \& Smith, 1973; Taft \& Forster, 1976, for positive findings; and Barron \& Pittenger, 1974; Forster \& Chambers, 1973; Frederiksen \& Kroll, 1976; Henderson, Coltheart, \& Woodhouse, 1973, for negative findings); although priming of syllabic items was observed in Dorfman (1994), this may not be true in the word identification task.

The second aim of the study was to examine some of the conditions that may affect nonword identification priming. Manipulations of surface features across study and test items were carried out to examine whether specific as opposed to abstract information is important in priming (Experiment 2). Examination of the effects of encoding on priming was carried out in Experiment 3, to investigate whether priming may differ, depending on whether orthographic or phonological analyses are carried out. Finally, in Experiment 4, the question of whether rearranging components of the stimuli affected priming was investigated in order to better understand the relative role of componential activation and componential integration.

\section{EXPERIMENT 1}

The primary purpose of Experiment 1 was to provide preliminary data on the effects of componential structure on priming of nonwords in the identification task. As in Dorfman (1994), nonwords with morphemic structure were formed out of either two stems (e.g., GEN + vIVE, COM +FLECT), a prefix attached to a stem (e.g., OB + SIST, $\mathrm{BE}+\mathrm{MIT}$ ), or a suffix attached to a stem (e.g., LUX + FUL, PLEN + TRON). Nonwords with syllabic structure were formed out of two syllables (e.g., FAS + NEY, GAR + BRID); no distinctions were made among different types of syllabic structure. Nonwords with pseudosyllabic structure were composed of syllable-like letter sequences that do not exist as units in English (e.g., ERK + TOFE, HIRN + PUSM). In view of the results of Dorfman (1994), priming was predicted for nonwords with morphemic and syllabic structure but not for nonwords with pseudosyllabic structure. If, however, the failure to observe priming for pseudosyllabic items in my previous study was due to response bias, priming should be evident for the pseudosyllabic condition, in addition to the morphemic and syllabic conditions. Finally, priming may be evident for morphemic items, but not for syllabic or pseudosyllabic items, if syllabic effects are difficult to produce in the word identification task.

An additional prediction was made with respect to overall identification performance: greater accuracy for morphemic and syllabic than for pseudosyllabic items. Previous research has shown that nonword stimuli are more readily identified when they contain familiar letter patterns (see, e.g., Mewhort, 1967; Miller, Bruner, \& Postman, 1954).

\section{Method}

The subjects performed a shallow-processing (vowel-counting) task on a list of nonwords of varying componential structure. ${ }^{4}$ 
They then completed a word identification task for old and new items.

Subjects. Twenty undergraduates from the University of Arizona participated in the experiment for credit in an introductory psychology course. All the subjects were native speakers of English and were tested individually.

Design. The general experimental design consisted of two within-group factors: type of componential structure (morphemic vs. syllabic vs. pseudosyllabic) and type of item (primed vs. unprimed).

Materials. The materials were based on those described in Dorfman (1994). The 54 target items from Experiment 4 of that study were used, together with an additional set of 54 items matched on length and componential structure. This resulted in two matched lists of 54 items. Each list contained 18 morphemic nonwords, 18 syllabic nonwords, and 18 pseudosyllabic nonwords. Morphemic nonwords were formed out of either two stems (e.g., CAL + TRUDE, GEN + VIVE), a prefix attached to a stem (e.g., SUB + VADE, OB + SIST), or a suffix attached to a stem (e.g., LUX+FUL, MORT + NESS). Syllabic nonwords were always formed out of two syllables (e.g., FAS + NEY, BUR + PAIGN). Pseudosyllabic nonwords were formed out of two syllable-like letter sequences that do not exist as syllables in English (e.g., ERK + TOFE, KUC + THOIM). The nonwords in the three structural conditions were matched for length. The first components ranged in length from two to four letters, and the second components ranged from three to five letters. The morphemes were taken from comprehensive lists of stems and affixes, and the syllables were taken from dictionary entries on the basis of the standard rules of syllabification. Pseudosyllables were selected by performing a search of the Kučera and Francis (1967) database and then confirming any match as not existing as a syllable in the dictionary. Nonwords were formed by randomly pairing the selected components of each subtype. Morphemes and syllables were always used in the position in which they normally occur in real words.

Half the subjects received the items from one list in the study phase, and half received the items from the other list. The unpresented list served as new items on the word identification test Thus, each of the items was presented equally often as an old and as a new item.

Procedure. The experiment was carried out on an IBM PS2 computer using the DMASTR display system developed by Forster and colleagues. This system synchronizes the timing of the display with the video raster. Upon arrival in the laboratory, the subjects were seated in front of the computer and given instructions about the experiment. All the subjects were given incidental learning instructions: They were told that the experiment was concerned with "how people process words" and were not informed that there would be a subsequent memory test. Each subject received a different pseudorandom arrangement of the 54 study items - that is, block-wise randomization that distributes items evenly across conditions. Eight buffer items were presented both before and after the study list. The subjects were instructed to count the number of vowels in each stimulus item and to say the number aloud. Their responses were recorded on a tape recorder. The subjects were told to respond as quickly and accurately as possible and to pay attention only to the vowels.

Directly upon completion of the processing task, the subjects were given instructions about the identification task. The subjects were led to believe that they were participating in a different experiment for which they were providing normative data. They were told that the experiment was concerned with "how people perceive words." The subjects were instructed that they would see a series of letter strings flashed very quickly on the screen and that their task was to write down as many of the letters as they could. They were given response booklets to record their responses. The subjects were encouraged to give a response for every item, guessing if necessary. Each subject received a different pseudorandom arrangement of the stimulus items.

The sequence of events for each trial was as follows. First, the item number appeared in the center of the screen. In DMASTR, this serves both as the fixation stimulus and as a means for providing the subjects with the appropriate stimulus number. The fixation stimulus remained on the screen until the subjects pressed the space bar. The target item was then presented for $171 \mathrm{msec}$, an exposure time that pilot work showed produced a performance level of approximately $50 \%$ correct. A mask of hash marks (\#) the same length as the target was then presented for $500 \mathrm{msec}$. A set of 12 practice items was used to acquaint the subjects with the task. The lst item was presented for $299 \mathrm{msec}$, an exposure time for which almost all subjects produced a correct response. The exposure time was then reduced by $14 \mathrm{msec}$ for each subsequent practice item. The time for the last 3 practice items was equivalent to the time for the critical items. The subjects were given feedback as to the correctness of their responses for the practice items but not for the critical items.

Because the computer used raster technology, all of the presentation durations were only approximate. The times were accurate to within $\pm 14 \mathrm{msec}$. This should have little impact on the results, since the variability in presentation duration is random.

\section{Results}

The data are summarized in Table 1. The first column shows the mean proportion of previously studied (Old) items identified correctly in the three structural conditions. The second column gives the mean proportion of unexposed (New) items identified correctly- that is, the baseline identification rate. The last column (Prm) gives the priming scores, or the mean difference between the old and new conditions. A response was scored as correct only if it matched the stimulus item completely. ${ }^{5}$ The analyses reported in this paper were based on both subject $\left(F_{1}, t_{1}\right)$ and item $\left(F_{2}, t_{2}\right)$ variability. The means and standard deviations presented in the tables were taken from the subject analyses. A significance level of .05 was used, unless otherwise stated. Any discrepancies between means may be attributed to rounding.

An analysis of variance (ANOVA) was first conducted on the priming scores. This analysis, as well as subsequent ones, included the counterbalancing scheme as a factor, to remove variability from the error term and increase experimental power (Pollatsek \& Well, 1995). ${ }^{6}$

Table 1

Word Identification Data: Experiment 1

\begin{tabular}{|c|c|c|c|}
\hline Structural Condition & Old & New & Priming \\
\hline \multicolumn{4}{|l|}{ Morphemic } \\
\hline$M$ & .57 & .48 & $.09 \uparrow$ \\
\hline$S D$ & .20 & .20 & - \\
\hline \multicolumn{4}{|l|}{ Syllabic } \\
\hline$M$ & .56 & .47 & $.09^{*}$ \\
\hline$S D$ & .17 & .19 & - \\
\hline \multicolumn{4}{|l|}{ Pseudosyllabic } \\
\hline$M$ & .16 & .13 & .03 \\
\hline$S D$ & .18 & .12 & - \\
\hline
\end{tabular}

Note-Old, mean proportion correct for previously studied items. New, mean proportion correct for nonstudied items. Dashes indicate data not applicable for measure. ${ }^{*} p<.05 .{ }^{\dagger} p<.01$ 
Despite numerically greater priming for morphemic (.09) and syllabic (.09) than for pseudosyllabic (.03) items, the main effect of componential structure did not achieve significance in either the subject $\left[F_{1}(2,36)=\right.$ $1.39, M S e=0.016, p=.262]$ or the item $\left[F_{2}(2,102)=\right.$ $\left.1.26, M S_{\mathrm{e}}=0.033, p=.289\right]$ analyses. Paired $t$ tests comparing the means for the old and new conditions, however, revealed significant priming for morphemic and syllabic items but not for pseudosyllabic items. Old morphemic items were identified correctly at a rate of .57 , in contrast to a base rate of .48 for new items $\left[t_{1}(19)=3.61\right.$, $\left.p<.01 ; t_{2}(35)=2.47, p<.05\right]$. Old syllabic items were identified correctly at a rate of .56, as opposed to a base rate of .47 for new items $\left[t_{1}(19)=2.79, p<.05 ; t_{2}(35)=\right.$ $2.91, p<.01]$. Old pseudosyllabic items were identified at a rate of .16 , in contrast to .13 for new items $\left[t_{1}(19)=\right.$ $\left.1.10, t_{2}(35)=1.32\right]$. Priming did not differ on the basis of the specific morphemic structure of the stimuli $\left[F_{1}(2,36)=1.64, M S_{\mathrm{e}}=0.051 ; F_{2}(2,30)=1.02, M S_{\mathrm{e}}=\right.$ $0.040]$.

A final analysis examined overall performance across old and new items in the three structural conditions. This analysis revealed better performance for morphemic (.53) and syllabic (.52) than for pseudosyllabic (.15) items $\left[F_{1}(2,38)=203.52, M S_{\mathrm{e}}=0.009 ; F_{2}(2,105)=36.00\right.$, $\left.M S_{\mathrm{e}}=0.094\right]$. A Newman-Keuls test confirmed that pseudosyllabic items differed from morphemic and syllabic items, which did not differ from each other.

\section{EXPERIMENT 2}

Experiment 1 replicated the general effects observed in Dorfman (1994): significant priming for nonwords formed out of familiar sublexical (morphemic and syllabic) components but not for nonwords formed out of unfamiliar pseudosyllabic elements. These results are consistent with the notion that implicit memory for novel words depends on the activation and integration of prior linguistic knowledge. The overall level of performance was greater for items formed out of familiar sublexical components than for items formed out of unfamiliar letter sequences. This suggests that identification of a letter string is facilitated when that string contains familiar letter patterns (Mewhort, 1967; Miller et al., 1954).

The difference in the base rates for pseudosyllabic items, as compared with morphemic and syllabic items, however, may compromise the interpretation of the priming effects: The failure to observe priming in the pseudosyllabic condition may be an artifact of floor effects. The purpose of Experiment 2 was to control for this possibility by increasing the presentation time for pseudosyllabic items until the base rates were matched across the three structural conditions. If priming is still not evident for the pseudosyllabic condition, this would provide more convincing evidence for the activation-integration view. If, however, priming is equivalent for the three structural conditions, this would suggest that priming is based on newly established episodic or perceptual representations.

A second goal of Experiment 2 was to examine the effect of a change in surface features (type case) on priming. In Dorfman (1994), I showed that priming of word judgments is affected minimally by a change in case across study and test items. Other researchers, moreover, have demonstrated that priming effects can be relatively abstract (see, e.g., Carr, Brown, \& Charalambous, 1989; Feustel et al., 1983; Graf, Shimamura, \& Squire, 1985; Scarborough et al., 1977). ${ }^{7}$ Such findings are consistent with the view that priming relies on activation of abstract preexisting representations, as opposed to the laying down of new, highly specific ones. Thus, if identification of nonwords is mediated by the activation and integration of preexisting sublexical units, one might expect priming to be relatively invariant across a change in case. If, on the other hand, priming is mediated by the formation of new episodic or perceptual representations, a change in case should reduce the overlap between the record encoded during the study phase and the item presented at the test phase, thereby reducing priming.

\section{Method}

Subjects. An additional 40 students from the University of Arizona participated in the experiment.

Design. The general experimental design consisted of one between-group factor, type of case (same vs. different), and one within-group factor, type of componential structure (morphemic vs. syllabic vs. pseudosyllabic). Twenty students were randomly assigned to each case condition.

Materials and Procedure. The materials were identical to those used in Experiment 1. The subjects in both case conditions were presented with the 54 stimulus items in uppercase and asked to count the number of vowels in each item. One group of subjects then received the identification test with the items switched to lower case, and another received the test with the items maintained in uppercase. The subjects in the different-case condition were not informed of any change in the appearance of the items. Upon completion of the processing task, all the subjects were given the identification test for 54 old and 54 new items. The morphemic and syllabic items were presented for $171 \mathrm{msec}$; the pseudosyllabic items were presented for $500 \mathrm{msec}$.

\section{Results}

The proportion of correctly identified old and new items and the priming scores are shown in Table 2. A mixed-factorial ANOVA was conducted on the priming scores. As expected, the main effect of case was nonsignificant $\left[F_{1}(1,36)=0.42, M S_{\mathrm{e}}=0.010 ; F_{2}(1,102)=\right.$ $\left.0.30, M S_{\mathrm{e}}=0.040\right]$, with priming no greater for the samecase $(.06)$ than for the different-case $(.05)$ condition. The main effect of componential structure did not achieve significance $\left[F_{1}(2,72)=1.29, M S_{\mathrm{e}}=0.020 ; F_{2}(2,102)=\right.$ $\left.1.24, M S_{\mathrm{e}}=0.040\right]$. Priming was .08 for morphemic items, .03 for syllabic items, and .04 for pseudosyllabic items. The case $\times$ structure interaction did not achieve significance $\left[F_{1}(2,72)=0.08, M S_{\mathrm{e}}=0.020 ; F_{2}(2,102)=\right.$ $\left.0.04, M S_{\mathrm{e}}=0.040\right]$. Priming did not differ on the basis of 
Table 2

Word Identification Data: Experiment 2

\begin{tabular}{llll}
\hline $\begin{array}{c}\text { Case and } \\
\text { Structural Condition }\end{array}$ & Old & New & Priming \\
\hline Same case & & & \\
Morphemic & & & \\
$M$ & .54 & .45 & $.09{ }^{\dagger}$ \\
$S D$ & .25 & .21 & - \\
Syllabic & & & \\
$M$ & .51 & .46 & .04 \\
$S D$ & .24 & .22 & - \\
Pseudosyllabic & & & \\
$M$ & .41 & .37 & .04 \\
$S D$ & .28 & .22 & - \\
Different case & & & \\
Morphemic & & & $.07^{*}$ \\
$M$ & .56 & .49 & - \\
$S D$ & .24 & .25 & .03 \\
Syllabic & & & - \\
$M$ & .54 & .51 & .04 \\
$S D$ & .25 & .21 & - \\
Pseudosyllabic & & & \\
$M$ & .49 & .45 & .24 \\
$S D$ & .24 & .24
\end{tabular}

Note-Old, mean proportion correct for previously studied items. New, mean proportion correct for nonstudied items. Dashes indicate data not applicable for measure. ${ }^{*} p<.05 . \quad{ }^{\dagger} p<.01$.

the specific structure of the morphemic items $\left[F_{1}(2,72)=\right.$ $\left.1.53, M S_{\mathrm{e}}=0.057 ; F_{2}(2,30)=1.20, M S_{\mathrm{e}}=0.044\right]$, nor did the case $\times$ structure interaction reach significance $\left[F_{1}(2,72)\right.$ and $\left.F_{2}(2,30)<1\right]$.

Table 2 shows that, for both case conditions significant priming occurred for morphemic items but not for syllabic or pseudosyllabic items. In the same-case condition, previously exposed morphemic items were identified at a rate of .54, as compared with a base rate of .45 , for a priming effect of 09 . This effect was significant by subjects $\left[t_{1}(19)=4.34, p<.001\right]$ and marginally significant by items $\left[t_{2}(35)=1.81, p=.078\right]$. Old syllabic items were identified at a rate of .51 , as compared with a base rate of .46 , for nonsignificant priming of .04 $\left[t_{1}(19)=\right.$ $\left.1.08, t_{2}(35)=0.89\right]$. Old pseudosyllabic items were identified .41 of the time, as compared with a base rate of .37 , for nonsignificant priming of $.04\left[t_{1}(19)=1.33\right.$, $\left.t_{2}(35)=0.66\right]$. In the different-case condition, old morphemic items were identified at a rate of .56 , in contrast to a base rate of .49 , yielding priming of .07 . This effect was significant by subjects $\left[t_{1}(19)=2.22, p<.05\right]$, and marginally significant by items $\left[t_{2}(35)=1.95, p=.059\right]$. Old syllabic items were identified at a rate of .54 , as compared with a base rate of .51 , for nonsignificant priming of $.03\left[t_{1}(19)=1.09, t_{2}(35)=0.90\right]$. Old pseudosyllabic items were identified at a rate of 49 , in contrast to a base rate of .45 , for nonsignificant priming of .04 $\left[t_{1}(19)=1.54, t_{2}(35)=0.98\right]$.

\section{EXPERIMENT 3}

Experiment 2 found priming for morphemic nonwords but not for syllabic or pseudosyllabic nonwords.
The magnitude of priming did not differ according to whether a studied item was tested in the same or a different type case. These results are consistent with the notion that priming relies on the activation and integration of abstract preexisting sublexical representations. However, they suggest that syllabic items may be less readily encoded, and hence less primeable, than morphemic items.

The latter conclusion, however, must remain tentative, given the conflicting findings for syllabic items in Experiment 1. In Experiment 3, I sought to replicate the findings from Experiment 2, as well as to examine conditions that may increase the likelihood of syllabic priming. The experiment was also intended to provide additional data to strengthen the conclusion that priming differs on the basis of the underlying componential structure of a stimulus. Support for this conclusion was only indirect in Experiments 1 and 2, in that differences between item types were inferred on the basis of whether significant priming effects were observed (i.e., whether performance differed for old and new items). A more definitive demonstration requires an observation of a significant difference between item types in an ANOVA on the priming scores. Due to power issues, it may be necessary to combine the data from multiple experiments to observe such an effect, as was the case in Dorfman (1994).

In the experiment, priming under two encoding conditions - the vowel-counting condition used in Experiments 1 and 2 and a naming condition in which the subjects pronounced the nonwords aloud-was examined. Vowel counting can be seen as a structural encoding task that depends on the visual analysis of a stimulus. Naming, by contrast, involves a phonological analysis of the stimuli. It was reasoned that providing additional cues to syllable structure (syllables are phonological as well as orthographic units) may foster the decomposition of the nonwords into their constituent syllables. In other words, changing the processing conditions may allow the system to parse according to an available but weakly activated division of component units. Syllable boundaries are difficult to identify in English (see Cutler, Mehler, Norris, \& Segui, 1986), and directing the subject's attention toward phonological aspects of the stimulus may facilitate segmentation. Consistent with this, in Dorfman (1994), where I obtained clearer evidence of syllabic priming, a task was used in which the subjects received explicit information about syllable boundaries (see GARBRIDGARTUME was one of the test items).

Phonological processing may also facilitate performance if priming of syllabic items is based on extraction of subsyllabic units. I raised this possibility in Dorfman (1994) on the basis of my failure to observe syllabic priming in several conditions and conflicting evidence from studies of word recognition as to whether syllables are represented in the lexicon (see, e.g., Barron \& Pittenger, 1974; Forster \& Chambers, 1973; Frederiksen \& Kroll, 1976; Henderson et al., 1973, for failures to find syllabic effects). Priming based on subsyllabic structures may occur unreliably, in that successful encoding of an item 
requires integration of multiple stimulus components. Processing the items phonologically may facilitate componential integration. Pseudosyllabic items (which contain familiar letters and letter clusters) may derive some benefit from phonological processing for the same reason. Consistent with this, a previous study demonstrated that priming of illegal nonwords is greater following a naming than following a vowel-counting task (Bowers, 1994).

\section{Method}

Subjects. An additional 40 students from the University of Arizona participated in the experiment.

Design. The general experimental design consisted of one between-groups factor, type of processing (vowel-counting vs. naming), and one within-group factor, type of componential structure (morphemic vs. syllabic vs. pseudosyllabic). Twenty students were randomly assigned to each processing condition.

Materials and Procedure. The materials were identical to those used in Experiments 1 and 2. The subjects in the vowel-counting condition were instructed to count the number of voweis in each of the 54 study items. The subjects in the naming condition were required to say aloud each of the study items. The procedure for the word identification task was identical to that used in Experiment 2.

\section{Results}

The proportion of correctly identified old and new items and the priming scores are shown in Table 3. A mixed-factorial ANOVA was conducted on the priming scores. The main effect of processing was nonsignificant $\left[F_{1}(1,36)=1.23, M S_{\mathrm{e}}=0.030 ; F_{2}(1,102)=1.83, M S_{\mathrm{e}}=\right.$ 0.035 ], with priming not differing for the vowel-counting $(.05)$ and naming (.08) conditions. The main effect of componential structure was marginally significant in both the subject analysis $\left[F_{1}(2,72)=2.86, M S_{\mathrm{e}}=0.017\right.$,

Table 3

Word Identification Data: Experiment 3

\begin{tabular}{cccc}
\hline $\begin{array}{c}\text { Processing and } \\
\text { Structural Condition }\end{array}$ & Old & New & Priming \\
\hline $\begin{array}{l}\text { Vowel-counting } \\
\text { Morphemic }\end{array}$ & & & \\
$M$ & .44 & .34 & $.10^{*}$ \\
$S D$ & .25 & .20 & - \\
Syllabic & & & .03 \\
$M$ & .42 & .39 & - \\
$S D$ & .22 & .21 & - \\
Pseudosyllabic & & & .00 \\
$M$ & .35 & .35 & - \\
$S D$ & .28 & .23 & \\
Naming & & & \\
Morphemic & & & \\
$M$ & .58 & .49 & $.09^{*}$ \\
$S D$ & .21 & .25 & - \\
Syllabic & & & \\
$M$ & .55 & .44 & $.11^{*}$ \\
$S D$ & .23 & .23 & - \\
Pseudosyllabic & & & \\
$M$ & .45 & .40 & $.05^{*}$ \\
$S D$ & .24 & .24 & -
\end{tabular}

Note-Old, mean proportion correct for previously studied items. New, mean proportion correct for nonstudied items. Dashes indicate data not applicable for measure. ${ }^{*} p<.05$. $p=.064]$, and the item analysis $\left[F_{2}(2,102)=3.01, M S_{\mathrm{e}}=\right.$ $0.032, p=.054]$. Across processing conditions, priming was .10 for morphemic items, .07 for syllabic items, and .03 for pseudosyllabic items. The processing $\times$ structure interaction did not achieve significance $\left[F_{1}(2,72)=\right.$ $\left.1.44, M S_{\mathrm{e}}=0.017 ; F_{2}(2,102)=0.81, M S_{\mathrm{e}}=0.035\right]$.

As shown in Table 3, there were some differences in the pattern of priming between the two processing conditions. The data for the vowel-counting condition were similar to those from Experiment 2. Old morphemic items were identified at a rate of .44 , as compared with a base rate of .34 , for a priming effect of .10 . This effect was significant both by subjects $\left[t_{1}(19)=2.65, p<.05\right]$ and by items $\left[t_{2}(35)=3.74, p<.01\right]$. Old syllabic items were identified at a rate of .42 , as compared with a base rate of .39 , for nonsignificant priming of $.03\left[t_{1}(19)=\right.$ $\left.1.41, t_{2}(35)=1.04\right]$. Old pseudosyllabic items were identified .35 of the time, as compared with a base rate of .35 , for nonsignificant priming of $.00\left[t_{1}(19)=0.10\right.$, $\left.t_{2}(35)=0.10\right]$. A different pattern emerged for the naming condition. Old morphemic items were identified at a rate of .58 , in contrast with a base rate of .49 , yielding priming of .09 $\left[t_{1}(19)=2.14 ; p<.05 ; t_{2}(35)=2.45, p<\right.$ .05]. Old syllabic items were identified at a rate of .55 , as compared with a base rate of .44 , for priming of .11 $\left[t_{1}(19)=2.85, p<.05 ; t_{2}(35)=2.36, p<.05\right]$. Old pseudosyllabic items were identified at a rate of .45 , in contrast with a base rate of .40 , for priming of .05 , an effect which was significant by subjects $\left[t_{1}(19)=2.62, p<.05\right]$, but not by items $\left[t_{2}(35)=0.97\right]$.

An analysis was next conducted that combined the priming data with those from Experiments 1 and 2. A mixed-factorial ANOVA revealed a significant main effect of componential structure in both the subject analysis $\left[F_{1}(2,188)=4.30, M S_{\mathrm{e}}=0.018, p=.015\right]$ and the item analysis $\left[F_{2}(2,102)=4.00, M S_{\mathrm{e}}=0.038, p=.021\right]$. Across experiments, priming was .09 for morphemic items, .06 for syllabic items, and .03 for pseudosyllabic items. Newman-Keuls tests showed that morphemic priming differed from pseudosyllabic priming; morphemic and syllabic priming did not significantly differ, nor did syllabic and pseudosyllabic priming. The effect of componential structure did not interact with experiment in either analysis (both $F \mathbf{S}<1$ ). When only the data from Experiment 2 were included (due to the possibility of floor effects in Experiment 1), similar effects were observed. The main effect of componential structure was significant by subjects $\left[F_{1}(2,152)=3.45, M S_{\mathrm{e}}=0.018\right.$, $p=.034]$ and by items $\left[F_{2}(2,102)=3.27, M S_{\mathrm{e}}=0.038\right.$, $p=.042]$. Newman-Keuls tests revealed the same pattern between means (the means were $.09, .05$, and .04, for morphemic, syllabic, and pseudosyllabic items, respectively). The structure $X$ experiment interaction was nonsignificant (both $F \mathrm{~s}<1$ ).

A meta-analysis across experiments was next conducted to provide further evidence of differences among item types. Meta-analysis conceptualizes experiments as a random factor, allowing one to generalize to the popula- 
tion of experiments from which the sample of experiments was drawn. It provides a more powerful test than tests based on individual experiments and goes beyond hypothesis testing by providing information about magnitude of effect. Effect sizes based on Cohen's $d$ were computed for the difference between old and new items for each structural condition for each of the five experimental groups in Experiments 1-3 (Hedges \& Olkin, 1985). The pooled standard deviation was used to compute $d$ values, pooling over old and new items separately for each structural condition. The average effect sizes were .39 for morphemic items, .28 for syllabic items, and .15 for pseudosyllabic items. According to Cohen's criteria, .2 is a small effect size, and .5 is a medium effect size. An ANOVA using experiments as the random factor was conducted to determine whether the mean effect sizes differed for the three structural conditions. An ANOVA on the effect size is a rather common approach to meta-analysis (Hedges \& Olkin, 1985; Rosenthal, 1991) and permits generalization to the population of experiments. This analysis revealed a significant effect of componential structure $\left[F(2,8)=6.74, M S_{\mathrm{e}}=0.089, p=.019\right]$. Newman-Keuls tests showed that the effect size for morphemic items differed from that for pseudosyllabic items; the effect sizes for morphemic and syllabic items and for syllabic and pseudosyllabic items did not reliably differ. Comparisons of each of the effect sizes against zero showed that all of the $d$ values were above chance $[t(4)=$ $13.80, p<.001$, for morphemic items; $t(4)=3.36, p<.05$, for syllabic items; and $t(4)=3.88, p<.05$, for pseudosyllabic items $].{ }^{8}$ An analysis using only the data from Experiments 2 and 3 obtained a similar pattern of results. The effect sizes were $.40, .23$, and .11 for morphemic, syllabic, and pseudosyllabic items, respectively. The difference between means achieved significance in the ANOVA $\left[F(2,6)=5.34, M S_{\mathrm{e}}=0.011, p=.047\right]$, and the pattern among means was the same in the Newman-Keuls test.

\section{EXPERIMENT 4}

Experiment 3 found syllabic (and some evidence of pseudosyllabic) priming following a naming task but not following a vowel-counting task. This suggests that phonological processing may foster encoding of syllabic or subsyllabic units. Both processing conditions, by contrast, produced robust morphemic priming. The general conclusion that priming differs on the basis of the underlying componential structure of a stimulus was confirmed statistically when the data were combined with those from the other experiments and when a metaanalysis was conducted across experiments. This outcome provides further evidence for the hypothesis that priming of novel words is based on the activation and integration of preexisting sublexical components

It remains possible, however, that priming is based on activation of individual components and does not require integration at all. Inconsistent with this notion, I showed in Dorfman (1994) that rearrangement of the components making up a nonword eliminated the priming effect in the word-judgment task. A similar effect was observed by Musen and Squire (1991) in a speeded reading task that tested priming of nonwords with rearranged syllables. Other studies have found partial priming of similarly structured items in speeded reading and word identification; these effects, however, occur under limited conditions (Light, La Voie, \& Kennison, 1995; Musen \& Squire, 1993). Conflicting findings have also been observed in studies examining identification priming of nonwords with rearranged letter components (see, e.g., Keane et al., 1995; Rueckl, 1990; see also Napps \& Fowler, 1987, for evidence that priming does not occur between form-related words). Given these mixed findings, it is important to examine the contribution of individual components to priming in the present paradigm. This was the purpose of Experiment 4.

The experiment was modeled very closely after Experiment 5 of Dorfman (1994). As in that experiment, a vowel-counting encoding procedure was used in which the subjects studied items whose components were either re-paired or reversed. In the re-paired condition, the subjects received items whose right-hand components were re-paired with left-hand components from other stimulus items. For instance, PILVIVE was the study item for the test item GENVIVE, and GENDOM was the study item for the test item PILDOM. In the reversed condition, the left- and right-hand components of each stimulus item were switched. Thus, VIVEGEN was the study item for GENVIVE, and DOMPIL was the study item for PILDOM. If priming is based on activation of individual components, rearrangement of the components making up a stimulus should have little effect on performance. However, if priming requires integration in addition to activation, a reduction in priming should be observed.

\section{Method}

Subjects. An additional 40 students from the University of Arizona participated in the experiment.

Materials and Procedure. The transformed stimulus items were constructed as follows. For the re-paired condition, the right-hand component from each stimulus item was matched with the lefthand component from a different stimulus item. For example, the VIVE from GENVIVE was paired with the PIL from PILDOM, and the PAIGN from BURPAIGN was paired with the WIL from WILBARD. For the reversed items, the left- and right-hand components from each individual stimulus item were transposed, such that the right-hand component became the beginning of the word and the left-hand component became the end of the word (e.g., VIVEGEN, PAIGNBUR). Note that with this transposition the components may be in positions that do not occur in real English words, as the original stimuli were not designed to allow randomization of components across position.

The procedure was identical to that used in the vowel-counting condition in Experiment 3, except that the subjects were given the rearranged stimulus items in the first phase of the experiment. They then were given the identification test with the original 108 items. Twenty students were randomly assigned to each transformation condition. 
Table 4

Word Identification Data: Experiment 4

\begin{tabular}{llll}
\hline $\begin{array}{l}\text { Transformation and } \\
\text { Structural Condition }\end{array}$ & Old & New & Priming \\
\hline Re-paired & & & \\
$\quad \begin{array}{l}\text { Morphemic } \\
M\end{array}$ & .48 & .45 & .03 \\
SD & .24 & .22 & - \\
Syllabic & & & \\
$M$ & .40 & .42 & -.03 \\
$S D$ & .21 & .25 & - \\
Pseudosyllabic & & & \\
$M$ & .34 & .33 & .01 \\
$S D$ & .19 & .18 & - \\
Reversed & & & \\
Morphemic & & & \\
$M$ & .47 & .47 & -.01 \\
$S D$ & .24 & .22 & - \\
Syllabic & & & \\
$M$ & .46 & .43 & .02 \\
$S D$ & .21 & .18 & - \\
Pseudosyllabic & & & .03 \\
$M$ & .39 & .36 & - \\
$S D$ & .25 & .21 &
\end{tabular}

Note-Old, mean proportion correct for previously studied items; New, mean proportion correct for nonstudied items. Dashes indicate data not applicable for measure.

\section{Results}

The data are shown in Table 4. A mixed-factorial ANOVA was first conducted. Neither the main effects of transformation and structure nor the transformation $x$ structure interaction reached significance (all $F \mathrm{~s}<1$ ). Overall, priming was .00 for the re-paired condition and .01 for the reversed condition. Across transformation conditions, priming was .01 for morphemic items, .00 for syllabic items, and .02 for pseudosyllabic items.

Paired $t$ tests showed that none of the means in either transformation condition differed significantly from baseline. In the re-paired condition, old morphemic items were identified at a rate of .48 , as compared with a base rate of .45 , for nonsignificant priming of $.03\left[t_{1}(19)=0.82\right.$, $\left.t_{2}(35)=0.85\right]$. Old syllabic items were identified at a rate of .40 , in contrast to a base rate of .42 , for a negative priming effect of $-.02\left[t_{1}(19)=-0.59, t_{2}(35)=-0.91\right]$. Old pseudosyllabic items were identified .34 of the time, as compared with a base rate of .33 , for nonsignificant priming of $.01\left[t_{1}(19)=0.34, t_{2}(35)=0.87\right]$. In the reversed condition, old morphemic items were identified at a rate of .47 , as opposed to a base rate of .47 , for zero priming $\left[t_{1}(19)=-0.15, t_{2}(35)=-0.16\right]$. Old syllabic items were identified at a rate of 46 , in contrast to a base rate of .43 , for nonsignificant priming of .03 $\left[t_{1}(19)=\right.$ $\left.0.83, t_{2}(35)=0.87\right]$. Old pseudosyllabic items were identified .39 of the time, as compared with a base rate of .36 , for nonsignificant priming of $.03\left[t_{1}(19)=0.91\right.$, $\left.t_{2}(35)=0.80\right]$.

\section{GENERAL DISCUSSION}

The results of the present study confirm the importance of underlying componential structure in implicit memory for novel words. Priming in an identification task is observed consistently when nonword stimuli are formed out of morphemic components; weaker, more variable effects are observed when nonwords are made up of syllabic or pseudosyllabic elements (Experiments 1,2 , and 3). Priming is insensitive to changes in the surface features across study and test items (Experiment 2) and depends on the integrity of both components of a previously exposed stimulus (Experiment 4).

These results provide further evidence for the notion, put forward by Dorfman (1994), that preexisting sublexical representations contribute to nonword priming. This is important, because it challenges the view that priming of novel information is based on entirely new representations laid down in episodic memory or in a domainspecific perceptual system (see, e.g., Jacoby, 1983; Roediger \& Blaxton, 1987; Schacter, 1990; Tulving \& Schacter, 1990). Implicit memory for new information is generally taken as strong evidence for a new representations view, since novel words, objects, and so on presumably have no preexisting representations in memory. The results of the present study provide clear evidence that preestablished knowledge can contribute to priming.

One way of interpreting these data is in terms of Mandler's $(1979,1980,1989)$ activation-integration theory of priming. According to this framework, priming of an ostensibly novel stimulus is based on activation of componential units that are parsed when an item is first studied (e.g., sublexical units in the case of a nonword, object parts in the case of a novel object). By virtue of their co-occurrence, these activated components are linked or integrated, producing a cohesive representation of the perceived stimulus. Priming reflects access to this representation in the course of processing a stimulus presented for identification.

An important prediction of the activation-integration model is that priming should differ depending on the nature of the elements comprising a novel stimulus. Thus, stimuli made up of clearly defined functional units may be expected to yield stronger priming than stimuli that are not formed from such units. Morphemes, for example, are elements of meaning that form the basis of all words. There is clear evidence from psycholinguistic studies that morphological information is extracted during word perception (see, e.g., Caramazza et al., 1988; Fowler et al., 1985; Murrell \& Morton, 1974; Rapp, 1992; Stanners et al., 1979; Taft \& Forster, 1975); further evidence for the functionality of the morpheme comes from studies of word production showing that shifts or exchanges of morphemes occur in speech errors (see, e.g., Garrett, 1980). Priming of a nonword such as GENVIVE, then, may be based on a process that activates and inte- 
grates the morphemic components GEN (found in genus, general, gender, etc.) and VIVE (found in survive, revive, vivify, etc.).

In theory, a similar kind of process might be said to operate on nonwords formed from syllables. Thus, an item such as GARBRID may be encoded by activating and integrating the syllabic components GAR and BRID. Such an argument, however, presupposes that the syllable serves as a perceptual unit, and it is unclear that this is the case. Psycholinguistic studies have failed to find consistent effects of syllabicity in word recognition, in contrast with clear evidence of morphological effects (see, e.g., Barron \& Pittenger, 1974; Eriksen et al., 1970; Forster \& Chambers, 1973; Frederiksen \& Kroll, 1976; Henderson et al., 1973; Prinzmetal et al., 1986; Rapp, 1992; Spoehr \& Smith, 1973; Taft \& Forster, 1976). This state of affairs may reflect the heterogeneity of syllables in English and the difficulty in determining their boundaries (compare with French: Cutler et al., 1986).

Syllabic effects in nonword priming, then, may require conditions that allow the system to parse syllables as such. For example, in Dorfman (1994), where I observed stronger effects for syllabic items than in the present study, test items consisted of pairs of nonwords in which the syllable boundaries were clearly delimited (e.g., GARBRID-GARTUME). The weaker effects in the present study may reflect the absence of cues to syllable structure in the word identification task. When processing conditions focus the subject's attention on phonological aspects of the stimulus, as in Experiment 3, the need for cues at test may be obviated. Phonological processing may foster the extraction, and consequent integration, of syllabic components, producing a representation that is more easily accessible at test. The finding of syllabic priming following visual processing in Experiment 1 may indicate that certain subjects are able to parse syllables even under very shallow processing conditions. This might indicate that syllables are more clearly integrated functional units for these particular individuals.

The inconsistency of syllabic nonword priming may also indicate that priming of such items, where it occurs, is based on activation of subsyllabic structures. I suggested this as an alternative mechanism of priming in my previous article on the basis of my failure to observe syllabic priming in two (of seven) conditions, together with the finding of numerically nonzero priming for pseudosyllabic items (which contain subsyllabic elements). Integration of subsyllabic components may be difficult to achieve, due to limits in the number of coordinate relations that can be formed or the quality of those relations (Mandler, 1979). The naming processing condition in Experiment 3 , which permits encoding of the stimuli in terms of phonological features, may foster componential integration by providing links between stimulus components.

Integration of pseudosyllabic stimuli may pose a still greater challenge to the cognitive system. By design, these items cannot be segmented into two discrete components (for example, ERKTOFE cannot be encoded by activating and integrating the units ERK and TOFE). The largest units that may be activated are at the level of either the letter cluster or the letter; these units, moreover, often occur in illegal positions. This may complicate considerably the task of componential integration. Thus, under phonological processing conditions, in which priming of syllabic items was .11, pseudosyllabic priming, though sig nificant, was only 05 .

In some sense, one can think of priming of novel information as varying according to the presumed level of familiarity of a stimulus. Thus, given a nonword of length $x$, a continuum of familiarity might range from stimuli composed of false font elements at one extreme to stimuli composed of morphemes at the other. Illegal letter strings, pseudosyllabic items, and syllabic items might fall somewhere in between. The present experiments have examined a limited portion of this continuum. Future research might profitably examine priming across the entire range.

The effects of componential structure in the present study suggest that the results of Dorfman (1994) were not an artifact of task-specific response bias. In that study, priming was assessed with a word judgment task in which the subjects were asked to select which of two nonwords was a better English word. One possible interpretation of the results (stronger priming for morphemic and syllabic than for pseudosyllabic items) was that priming of pseudosyllabic items was masked: The subjects may have been unable to make a judgment as to which of two poor exemplars of an English word was the better one. The finding that componential structure affects priming in an identification task, in which no such judgment is required, suggests that my previous results were related to sublexicality and not to peculiarities of the word judgment task.

Experiment 2 provides further evidence for the role of preexisting sublexical components in priming of novel words. That experiment demonstrated that priming was unaffected by a change in surface features (type case) across the study and test items. This finding is difficult to reconcile with the view that priming is based on a new, highly specific record of the global structure of a stimulus. It is more naturally accommodated by the view that priming is based on the activation and integration of $a b-$ stract sublexical units.

Other studies provide converging evidence for the importance of preexisting knowledge in implicit memory for novel information. In the case of nonwords, the vast majority of studies have observed priming using orthographically and phonologically legal stimuli in which one or two letters of a real word are replaced (e.g., MALK; Feustel et al., 1983; Musen \& Squire, 1991; Rueckl, 1990). Such items may be encoded through interactive activation processes operating on representations of orthographically related words and individual letter units (McClelland \& Rumelhart, 1981) or through processing of subsyllabic structures (Treiman, 1986). There is also evidence suggesting that nonword priming is enhanced 
when items make contact with preexisting semantic representations. Thus, Cermak et al. (1991) showed that priming in amnesia is greater for pseudowords that are homophones of real words (e.g., PHAIRE) than for typical pseudowords.

Like the present experiments, several studies have shown that priming is reduced or absent when nonwords are orthographically or phonologically illegal (Challis et al., 1992; Rugg \& Nagy, 1987; Scarborough et al., 1977; Schacter, Rapscak, et al., 1990; but see Bowers, 1994; Keane et al., 1995). Challis et al. observed priming in word fragment completion for regular nonwords such as CHOCEL but not for irregular nonwords such as BNEFKR. Similar effects were found by Scarborough et al., using a continuous lexical decision task. Rugg and Nagy observed modulations of event-related potentials for legal but not illegal letter strings presented in immediate succession in a lexical decision-type paradigm. Finally, Schacter et al. obtained word identification priming for words but not for illegal nonwords (legal nonwords were not tested) in a case study of a letter-by-letter reader. Although suggestive, some caution is required in generalizing from these studies to the present case of long-term priming effects in normal cognition, because of some very real differences in procedure.

Studies in the nonverbal domain provide further evidence for the importance of prior knowledge in implicit memory for new information. In experiments of novel object priming, Schacter and his colleagues (e.g., Schacter, Cooper, \& Delaney, 1990) have observed that implicit memory occurs for objects that are structurally possible but not for ones that are structurally impossible (see Ratcliff \& McKoon, 1995, for a critique of these findings, and Schacter \& Cooper, 1995, for a response). Williams and Tarr (1997) demonstrated that priming of impossible objects, where it occurs, depends critically on the number of possible parts within an object (see Seamon et al., 1995, for a related view). In a study using novel two-dimensional figures, Kersteen-Tucker (1991) showed that priming occurs consistently for symmetrical polygons but not for asymmetrical ones. Gunning, Raz, and Dorfman (1996) observed that the priming of novel line patterns found by others (e.g., Musen \& Treisman, 1990) only occurs for items that are judged to be "familiar" by subjects preexperimentally.

At first glance, the results of the present experiments seem at odds with two other recent studies investigating implicit memory for novel words (Bowers, 1994; Keane et al., 1995). Bowers (Experiment 3) reported that priming in an identification task occurred for illegal nonwords (e.g., XYKS) in addition to legal nonwords (e.g., KERS), consistent with a new representations view. However, inspection of Bowers's data shows that priming was greater for legal than for illegal nonwords. This was particularly true under structural processing conditions, similar to those used in the present study (counting the vowels and enclosed spaces of an item); priming was .16 for legal nonwords, as compared with .07 for illegal non- words. Similar to the present Experiment 3, the difference between legal and illegal items was reduced following a phonetic processing task (pronouncing an item and rating how difficult it was to do so). Under these conditions, priming was .16 for legal nonwords, as compared with .13 for illegal nonwords. This latter finding suggests that the subjects drew on prior linguistic knowledge in order to encode the illegal items.

In an investigation of implicit memory in amnesia, Keane et al. (1995) observed a similar priming effect for illegal nonwords. Both amnesic patients and controls showed identification priming for three-letter consonant strings following two presentations of the stimuli. Thus, like Bowers's (1994) data, this study suggests that priming can extend to illegal nonwords - at least after multiple stimulus presentations. Importantly, however, Keane et al. did not include legal nonwords for comparison purposes; thus, one cannot assess whether the extent of priming was comparable for illegal and legal items, as is required to disconfirm the activation hypothesis (see Hamann \& Squire, 1997, for recent amnesia data suggesting an advantage for legal items).

It is important to consider what factors might underlie the discrepancies between the foregoing studies and my own. One possible explanation derives from differences in the length of the test stimuli. In my studies, priming was generally not observed for illegal pseudosyllabic items five to eight letters in length; Bowers (1994) and Keane et al. (1995) did observe illegal nonword priming for items three or four letters long (see also Scarborough et al., 1977). Other studies using letter strings similar in length to those used in the present study also failed to observe illegal nonword priming (Rugg \& Nagy, 1987; Schacter, Rapscak, et al., 1990). This is just what one might expect if priming of illegal nonwords is based on representations that are constructed from individual letter components (or, perhaps, letter clusters). Integration processes may be constrained to encode a limited number of informational chunks; thus, illegal nonword priming may be observed for three- and four-letter strings but not for longer ones.

Another possible account of the conflicting data has been offered by Keane et al. (1995). Briefly, they argue that discrepancies between studies may reflect differences in the processes and representations invoked in different priming tasks. For example, they suggest that priming in the word judgment paradigm may be based on lexical priming processes that are sensitive to sublexical representations. Priming in the identification task, by contrast, may be based on perceptual processes that operate on low-level (letter or featural) representations. Recent work in cognitive neuroscience has implicated two neural systems that may be important in word and nonword priming-one in the left occipital cortex, which is thought to be specialized for the processing of abstract, componential information, and another in the right occipital cortex, which is said to be dedicated to the processing of specific, holistic information (cf. Mar- 
solek, Schacter, \& Nicholas, 1996; Posner \& Raichle, 1994). The former system seems to play a role in the processing of words and wordlike stimuli; the latter system has been implicated in the processing of words, legal and illegal nonwords, and nonlinguistic symbols. Keane et al. suggest that word judgment and identification priming may draw on the left- and right-hemisphere systems, respectively. As the authors acknowledge, however, this kind of model has difficulty accounting for findings of reduced priming of illegal items in the identification task (Schacter, Rapscak, et al., 1990). Thus, it does not provide a ready explanation for my failure to obtain consistent pseudosyllabic priming in the present set of experiments.

Nevertheless, it could be argued that the task conditions in the present experiments minimized the role of the right-hemisphere system. The exposure times that were employed were considerably longer than those used by Bowers (1994) and Keane et al. (1995). Under such conditions, it is possible that identification priming is more likely to engage the left occipital system (or perhaps some higher level system). If this is the case, one might expect to observe a sensitivity to sublexical factors similar to that which is observed in the word judgment task. Other studies suggest that identification priming need not be based in the specific right-hemisphere system. For example, Graf and Ryan (1990) showed that font-specific priming effects only occurred when subjects engaged in an orienting task focusing on perceptual aspects of a stimulus; processing an item for meaning produced abstract effects. Bowers (1996) found no evidence of casespecific priming of visually dissimilar words studied in uppercase and tested in lowercase (e.g., RAGE/rage); priming of visually dissimilar pseudowords (e.g., NEGA/ nega) was partially reduced by a change in case. These latter findings suggest an additional possibility: The role of each system may depend on the structure of a particular stimulus. Thus, it may be argued that the greater the likelihood of activating preexisting lexical or sublexical codes, the greater the involvement of the left-hemisphere system. This might help to explain other findings indicating that identification priming is stronger for legal than for illegal items with shorter display times (Bowers, 1994; Hamann \& Squire, 1997).

This modified perceptual representations account of priming can be seen as complementary to the activationintegration view. Indeed, one can think of activation and integration processes operating on sublexical components as very similar to the processes of the visual word form system as it was first described by Warrington and Shallice (1980). Those authors describe a left-hemisphere system whose function is to parse letter strings into ordered familiar units (e.g., graphemes, syllables, morphemes, whole words) and categorize those units visually. Note that this is very different from Schacter's ( 1990 ; Tulving \& Schacter, 1990) conception of a word form system as a system that establishes new, specific representations of a stimulus. Activation and integration processes operating on letter components, it follows, may be based in the specific right-hemisphere system, as described by Keane and her colleagues (1995).

Although I have argued that the priming effects observed in this study were based on activation and integration of sublexical components, a less interesting possibility remains. Given the relatively long exposure times, explicit, as opposed to implicit, memory processes may have mediated the observed effects. This possibility seems remote, given the fact that shallow processing tasks were used in all the experiments. Under such conditions, explicit retrieval processes have little information on which to operate. Thus, in Mandler, Hamson, and Dorfman (1990), we showed that, after a vowel-counting encoding task, the subjects recalled only $5 \%$ of the items from a list of categorized words (in contrast to $39 \%$ following semantic encoding). This percentage is likely to be even lower with the noncategorized nonwords used in the present study. Also inconsistent with the role of explicit memory, postexperimental interviews showed that none of the subjects noticed a connection between the processing and identification tasks. Finally, Schacter, Rapscak, et al. (1990) observed that identification priming with similar exposure durations was not influenced by variables affecting explicit memory.

It is also possible that other factors aside from sublexical ones mediated the present effects. For example, activation of multiple whole words may have contributed to priming, since items formed out of morphemes (or syllables) are more likely to activate real words than are items composed of pseudosyllables. Inconsistent with such a hypothesis is the finding in Experiment 4 that priming was eliminated by recombining the components of a stimulus. If priming is based on multiple whole words, disruption of the relations among components should not impact on performance. It remains possible that differences in orthographic characteristics of the stimuli contributed to differential priming effects; for example, Seidenberg (1987) has argued that putative sublexical effects in word recognition are an artifact of the frequency and distribution of letter patterns. Although the present data cannot rule out such an interpretation, I have shown in a subsequent (word judgment) study that sublexical effects remain when the different item types are matched in terms of bigram and trigram frequencies (Dorfman, 1998). In addition, Rapp (1992) demonstrated that sublexical effects in word recognition cannot be accounted for in terms of differences in bigram troughs. Finally, it is unlikely that the present effects reflected differential processing time in the study phase for the different item types. If anything, the subjects would have committed extra processing time to irregular pseudosyllabic items, producing an outcome of stronger, not weaker, priming.

The results of Experiment 4 suggest that priming relies not just on activation but also on integration of sublexical units. In keeping with my previous findings, nonword priming was eliminated when the components of an item were re-paired or reversed. This indicates that 
the present effect is not based on activation of individual components; rather, it requires integration of components into a unitized representation. This interpretation is similar to Biederman's proposal that visual object priming relies on a representation of activated components in specified relations (Biederman \& Cooper, 1991; see Hummel \& Biederman, 1992, for a neural network implementation). According to this view, object priming is based on a geon assembly layer, which represents object components (e.g., cylinders, bricks) and their relations (e.g., below, above). Biederman has suggested that it may be computationally advantageous for long-term priming (as in the case of an implicit memory study) to be based on this level of representation, as opposed to residual activation of componential representations. Short-lived componential activation may prove beneficial to the system, in that componential units need to be recruited frequently in the service of encoding novel arrangements of components. In the present context, then, it may be argued that activation of sublexical components shows a similar short-lived effect and that longterm priming of nonwords relies on a representation of sublexical components and the relations between them (see Bower, 1996, for a similar proposal based on reactivation theory).

It should be clear from this discussion that the kind of priming involved in this study is new association priming - that is, priming based on new links between component items. New association priming has been demonstrated most commonly with pairs of unrelated words (e.g., WINDOW-REASON), in word-stem completion (e.g., Graf \& Schacter, 1985; Schacter \& Graf, 1986), speeded reading (Moscovitch, Winocur, \& McLachlan, 1986), and, more recently, word identification (e.g., Gabrieli, Keane, Zarella, \& Poldrack, 1997). In contrast with the present findings, such studies generally obtain some priming for recombinations of component words. This suggests that residual activation of word units may persist longer than that of sublexical units.

New association priming has also been investigated in several other studies using nonword stimuli. In a study of amnesia, Musen and Squire (1991) observed priming in a continuous speeded reading task for nonwords such as LOCAPIC that were formed by replacing one letter from each syllable of a word. Similar to the present study, no priming was found for items that consisted of recombinations of the stimulus components (e.g., LOCAPION). In a subsequent study using more clearly defined components, Musen and Squire (1993) failed to observe either new association or component priming for compound nonwords (e.g., JAMDIRT) repeated once in speeded reading; no priming was found either using a two-phase word identification task (although there was evidence of component priming collapsing across amnesic and control groups). When items were repeated 10 times in speeded reading (identification was not tested), new association priming was observed, as was partial priming of re- arranged stimuli. A similar effect was observed in a study of normal aging by Light et al. (1995) for speeded reading of compound nonwords formed from words (e.g., WAYGIRL) or syllables (e.g., KENSESS). The syllabic effect, moreover, was observed with as few as two repetitions of the stimuli. Nevertheless, an experiment using a standard two-phase design failed to reveal significant priming of individual syllables, even though items were presented 6 times at study. Thus, although activation of individual sublexical units may contribute to priming of novel words, this may only be true in continuous priming paradigms in which little time intervenes between repetitions of a stimulus.

Psycholinguistic studies using short-term repetition priming paradigms have also found evidence for componential priming of sublexical units. For example, in a classic study, Murrell and Morton (1974) showed that priming in a continuous tachistoscopic identification task occurred when primes and targets were related morphologically (e.g., BORED/BORING) but not when they were related visually (e.g., BORN/BORING). Stanners et al. (1979) found that morphologically complex words such as PROGRESS were partially primed in a lexical decision task by presentation of words sharing either a prefix (PROFESS) or stem (REGRESS). Similar kinds of effects were observed for syllables and syllable-like units by Lima and Pollatsek (1983), also using a lexical decision paradigm. For example, BURDEN was primed by BUR and BURD, and HOLTER was primed by HOL and HOLT. At the subsyllabic level, Bowey (1990) observed rime priming effects in a masked priming procedure: CLIP was primed by IP, but DUSK was not primed by SK.

These kinds of findings, together with the results of the present study, provide converging evidence for the importance of sublexical components in priming and implicit memory. Componential units may be important not only for the processing of linguistic stimuli but also in visual perception and other cognitive domains. Primitive components, ranging from lines and angles to morphemes and geons, form the basis of all perceptual events. In a sense, very little of what we encounter in the world is novel, and it is a misnomer to talk about implicit memory for novel information.

\section{REFERENCES}

Barron, R. W., \& Pittenger, J. B. (1974). The effect of orthographic structure and lexical meaning on same-different judgments. Quarterly Journal of Experimental Psychology, 26, 566-581.

BiedermaN, I. (1987). Recognition-by-components: A theory of human image understanding. Psychological Review, 94, 115-147.

Biederman, I., \& Cooper, E. E. (1991). Priming contour-deleted images: Evidence for intermediate representations in visual object recognition. Cognitive Psychology, 23, 393-419.

Bower, G. H. (1996). Reactivating a reactivation theory of implicit memory. Consciousness \& Cognition, 5, 27-72.

Bowers, J. S. (1994). Does implicit memory extend to legal and illegal nonwords? Journal of Experimental Psychology Learning, Memory, \& Cognition, 20, 534-549.

BowERS, J. S. (1996). Different perceptual codes support priming for 
words and pseudowords: Was Morton right all along? Journal of Experimental Psychology: Learning, Memory: \& Cognition, 22, 13361353.

BOWEY, J. A. (1990). Orthographic onsets and rimes as functional units of reading. Memory \& Cognition. 18, 419-427.

Caramazza, A., Laudanna, A., \& Romani, C. (1988). Lexical access and inflectional morphology. Cognition. 28, 297-332.

Carr, T. H., Brown, J. S., \& Charalambous, A. (1989). Repetition and reading: Perceptual encoding mechanisms are very abstract but not very interactive. Journal of Experimental Psychology: Learning, Memory, \& Cognition, 15, 763-778.

Cermak, L. S., Talbot, N., Chandler, K., \& Wolbarst, L. R. (1985) The perceptual priming phenomenon in amnesia. Neuropsychologia, 23, 615-622.

Cermak, L. S., Verfaellie, M., Milberg, W., Letourneau, L., \& BLACKFORD, S. (1991). A further analysis of perceptual identification priming in alcohol Korsakoff patients. Neuropsychologia, 29, 725-736.

Challis, B. H., Jaciw, M., \& Pivetta, C. E. (1992, November). Mechanisms underlying priming on word-and nonword-fragment completion. Paper presented at the 33rd Annual Meeting of the Psychonomic Society, St. Louis.

Cutler, A., Mehler, J., Norris, D., \& Segui, J. (1986). The syllable's differing role in the segmentation of French and English. Journal of Memory \& Language, 25, 385-400.

DiAmond, R., \& RoziN, P. (1984). Activation of existing memories in the amnesic syndromes. Journal of Abnormal Psychology, 93, 98105

Dorfman, J. (1994). Sublexical components in implicit memory for novel words. Journal of Experimental Psychology: Learning, Memory, \& Cognition, 20, 1108-1125.

DORFMAN, J. (1998). Unitization of sublexical components in implicit memory for novel words. Manuscript submitted for publication.

Eriksen, C. W., Pollack, M., \& Montague, W. (1970). Implicit speech: Mechanism in perceptual encoding? Journal of Experimental Psychology, 84, 502-507.

Feustel, T. C., Shiffrin, R. M., \& Salasoo, A. (1983). Episodic and lexical contributions to the repetition effect in word identification. Journal of Experimental Psychology: General, 112, 309-346.

Forster, K. I., \& Chambers, S. M. (1973). Lexical access and naming time. Journal of Verbal Learning \& Verbal Behavior, 12, 627-635.

FORSTER, K. I., \& TAFT, M. (1994). Bodies, antibodies, and neighborhood density effects in masked form-priming. Journal of Experimental Psychology: Learning, Memory, \& Cognition, 20, 844-863.

Fowler, C. A., Naprs, S. E., \& Feldman, L. (1985). Relations among regular and irregular morphologically related words in the lexicon as revealed by repetition priming. Memory \& Cognition, 13, 241-255.

Frederiksen, J. R., \& Kroll, J. F. (1976). Spelling and sound: Approaches to the internal lexicon. Journal of Experimental Psychology: Human Perception \& Performance, 2, 361-379.

Gabrieli, J. D. E., Keane, M. M., Zarella, M. M., \& Poldrack, R. A (1997). Preservation of implicit memory for new associations in global amnesia. Psychological Science, 8, 326-329.

GarReTT, M. (1980). Levels of processing in sentence production. In B. Butterworth (Ed.), Language production (Vol. 1, pp. 177-220). London: Academic Press.

Graf, P., \& Mandler, G. (1984). Activation makes words more accessible but not necessarily more retrievable. Journal of Verbal Learning \& Verhal Behavior. 23, 553-568.

GRaF, P., \& RYAN, L. (1990). Transfer-appropriate processing for implicit and explicit memory. Journal of Experimental Psychology: Learning, Memory, \& Cognition, 16, 978-992.

Graf, P., \& SChacter, D. L. (1985). Implicit and explicit memory for new associations in normal and amnesic subjects. Journal of Experimental Psychology: Learning, Memory: \& Cognition, 11, 501-518.

Graf, P., Shimamura, A. P., \& Squire, L. R. (1985). Priming across modalities and priming across category levels: Extending the domain of preserved function in amnesia. Journal of Experimental Parchology: Learning, Menom: \& Cognition, 11, 386-396.

Ginning, F, M.. Raz. N., \& Dorfmai, J. (1996. April). Effects of age, familiarity, and levels-of-processing on implicit and explicit memory for novel patterns. Paper presented at the sixth biennial Cognitive Aging Conference, Atlanta.

HAist, F., Musen, G., \& SQuire, L. R. (1991). Intact priming of words and nonwords in amnesia. Psychobiology, 19, 275-285.

HamanN, S., \& SQuire, L. R. (1997). Intact priming for novel perceptual representations in amnesia. Journal of Cognitive Neuroscience. 9, 699-713.

HAYES-ROTH, B. (1977). Evolution of cognitive structures and processes. Psychological Review, 84, 260-278.

HEDGES, L. V., \& OLKIN, I. (1985). Statistical methods for meta-analysis. New York: Academic Press.

Henderson, L., Coltheart, M., \& Woodhouse, D. (1973). Failure to find a syllabic effect in number naming. Memory \& Cognition, 1 , 304-306.

Hochberg, J., \& Peterson, M. A. (1987). Piecemeal organization and cognitive components in object perception: Perceptually coupled responses to moving objects. Journal of Experimental Psychology: General, 116, 370-380

Hummel, J. E., \& Biederman, I. (1992). Dynamic binding in a neural network for shape recognition. Psychological Review, 99, 480-517.

JACOBY, L. L. (1983). Remembering the data: Analyzing interactive processes in reading. Journal of Verbal Learning \& Verbal Behavior, 22, 485-508.

JaCoBy, L. L., Woloshyn, V.. \& Kelley, C. (1989). Becoming famous without being recognized: Unconscious influences of memory produced by divided attention. Journal of Experimental Psychology: General, 118, 115-125.

Johnson, M. K., Kim, J. K., \& Risse, G. (1985). Do alcoholic Korsakoff's syndrome patients acquire affective reactions? Journal of Experimental Psychology: Learning, Memory, \& Cognition, 11, $22-$ 36 .

Keane, M. M., Gabrieli, J. D. E., Noland, J. S., \& McNealy, S. I. (1995). Normal perceptual priming of orthographically illegal nonwords in amnesia. Journal of the International Neuropsychological Society, 1, 425-433.

KERSTEEN-TUCKER, Z. (1991). Long-term repetition priming with symmetrical polygons and words. Memory \& Cognition, 19, 37-43.

KLAPP, S. T. (1971). Implicit speech inferred from response latencies in same-different decisions. Journal of Experimental Psychology. 91, 262-267.

KuČERA, H., \& Francis, W. N. (1967). Computational analyis of present-day American English. Providence, Rl: Brown University Press.

Light, L. L., La VoIE, D., \& KenNison, R. (1995). Repetition priming of nonwords in young and older adults. Journal of Experimental Psychology: Learning, Memory, \& Cognition, 21, 327-346.

Lima, S. D., \& Pollatsek, A. (1983). Lexical access via an orthographic code? The basic orthographic syllabic structure (BOSS) reconsidered. Journal of Verbal Learning \& Verbal Behavior, 22, 310 332.

MANDLER, G. (1979). Organization and repetition: Organizational principles with special reference to rote learning. In L. G. Nilsson (Ed.), Perspectives on memory research (pp. 293-327). Hillsdale, NJ: Erlbaum

MandLER, G. (1980). Recognizing: The judgment of previous occurrence. Psychological Review, 87, 252-271.

MANDler, G. (1989). Memory: Conscious and unconscious. In P. R. Solomon, G. R. Goethals, C. M. Kelley, \& B. R. Stephens (Eds.), Memory: An interdisciplinary approach (pp. 84-106). New York: Springer-Verlag.

Mandler, G., Hamson, C. O., \& Dorfman, J. (1990). Tests of dual process theory: Word priming and recognition. Quarterly Journal of Experimental Psychology. 42A, 713-739.

Marsolek, C. J., Schacter, D. L., \& Nicholas, C. D. (1996). Formspecific visual priming for new associations in the right cerebral hemisphere. Memory \& Cognition, 24, 539-556.

McClelland, J. L., \& Rumelhart, D. E. (1981). An interactive activation model of context effects in letter perception: Pt. I. An account of basic findings. Pstchological Review: 88, 375-407. 
MEWhort, D. J. K. (1967). Familiarity of letter sequences, response uncertainty, and the tachistoscopic recognition experiment. Canadian Journal of Psychology, 21, 309-321.

Miller, G. A., Bruner, J. S., \& Postman, L. (1954). Familiarity of letter sequences and tachistoscopic identification. Journal of General Psychology, 50, 129-139.

MORTON, J. (1979). Facilitation in word recognition: Experiments causing change in the logogen models. In P. A. Kolers, M. E. Wrolstad, \& H. Bouma (Eds.), Processing of visible language (Vol. 1, pp. 259-268). New York: Plenum.

Moscovitch, M., WinocuR, G., \& MCLachlan, D. (1986). Memory as assessed by recognition and reading time in normal and memoryimpaired people with Alzheimer's disease and other neurological disorders. Journal of Experimental Psychology: General, 115, 331-347.

MURRELL, G., \& MORTON, J. (1974). Word recognition and morphemic structure. Journal of Experimental Psychology, 102, 963-968.

Musen, G., \& Squire, L. R. (1991). Normal acquisition of novel verbal information in amnesia. Journal of Experimental Psychology. Learning. Memory, \& Cognition, 17, 1095-1104.

Musen, G., \& SQuire, L. R. (1993). On the implicit learning of novel associations by amnesic patients and normal subjects. Neuropsychology, 7, 119-135.

Musen, G., \& Treisman, A. (1990). Implicit and explicit memory for visual patterns. Journal of Experimental Psychology: Learning, Memory, \& Cognition, 16, 127-137.

NAPPS, S. E., \& Fowler, C. A. (1987). Formal relationships among words and the organization of the mental lexicon. Journal of Psycholinguistic Research, 16, 257-272.

Petersen, S. E., Fox, P. T., Snyder, A. Z., \& Raichle, M. E. (1990). Activation of extrastriate and frontal cortical areas by visual words and word-like stimuli. Science, 249, 1041-1044.

Pollatsek, A., \& Well, A. D. (1995). On the use of counterbalanced designs in cognitive research: A suggestion for a better and more powerful analysis. Journal of Experimental Psychology: Learning. Memory, \& Cognition, 21, 785-794.

Posner, M. I., \& Raichle, M. (1994). Images of mind. New York: Scientific American Library.

Prinzmetal, W., Treiman, R., \& Rho, S. H. (1986). How to see a reading unit. Journal of Memory \& Language, 25, 461-475.

RAPP, B. C. (1992). The nature of sublexical orthographic organization: The bigram trough hypothesis examined. Journal of Memory \& Language, 31, 33-53.

RATCLIFF, R., \& McKoon, G. (1995). Bias in the priming of object decisions. Journal of Experimental Psychology: Learning, Memory, \& Cognition, 21, 754-767.

Richardson-Klavehn, A., \& BJork, R. A. (1988). Measures of memory. Annual Review of Psychology, 39, 475-543.

Roediger, H. L., III, \& Blaxton, T. A. (1987). Effects of varying modality, surface features, and retention interval on priming in word-fragment completion. Memory \& Cognition, 15, 379-388.

Roediger, H. L., III, \& MCDermott, K. (1993). Implicit memory in normal human subjects. In H. Spinnler \& F. Boller (Eds.), Handbook of neuropsychology (Vol. 8, pp. 63-131). Amsterdam: Elsevier.

ROSENTHAL, R. (1991). Meta-analytic procedures for social research (rev. ed.). Thousand Oaks, CA: Sage.

RUECKL, J. G. (1990). Similarity effects in word and pseudoword repetition priming. Journal of Experimental Psychology: Learning Memory, \& Cognition, 16, 374-391.

RUGG, M. D., \& NAGY, M. E. (1987). Lexical contribution to nonwordrepetition effects: Evidence from event-related potentials. Memory \& Cognition, 15, 473-481.

Salasoo, A., Shiffrin, R. M., \& Feustel, T. C. (1985). Building permanent memory codes: Codification and repetition effects in word identification. Journal of Experimental Psychology: General, 114 $50-77$

Santa, J. L., Santa, C, \& Smith, E. E. (1977). Units of word recognition: Evidence for the use of multiple units. Perception \& Psychophysics. 22, 585-591

Scarborough, D. L., Cortese, C., \& Scarborough, H. S. (1977). Frequency and repetition effects in lexical memory. Journal of Experimental Psychology: Human Perception \& Performance. 4, 1-17.
SCHACTER, D. L. (1987). Implicit memory: History and current status Journal of Experimental Psychology: Learning, Memory, \& Cognition, 13, 501-518.

SCHACTER, D. L. (1990). Perceptual representation systems and implicit memory: Toward a resolution of the multiple memory systems debate. In A. Diamond (Ed.), The development and neural bases of higher cognitive functions (Annals of the New York Academy of Sciences, Vol. 608, pp. 545-571). New York: New York Academy of Sciences.

SCHACTER, D. L., \& COOPER, L. A. (1995). Bias in the priming of object decisions: Logic, assumption, and data. Journal of Experimental Psychology: Learning, Memory, \& Cognition, 21, 768-776.

Schacter, D. L., CoOper, L. A., \& Delaney, S. M. (1990). Implicit memory for unfamiliar objects depends on access to structural descriptions. Journal of Experimental Psychology: General, 119, 5-24.

SCHACTER, D. L., \& GRAF, P. (1986). Effects of elaborative processing on implicit and explicit memory for new associations. Journal of Experimental Psychology: Learning, Memory, \& Cognition, 12, 432444.

Schacter, D. L., Rapscak, S. Z., Rubens, A. B., Tharan, M., \& LaGUNA, J. (1990). Priming effects in a letter-by-letter reader depend upon access to the word form system. Neuropsychologia, 28, 10791094.

Seamon, J. G., Williams, P. C., Crowley, M. J., Kim, I. J., Langer, S. A., ORNE, P. J., \& Wishengrad, D. L. (1995). The mere exposure effect is based on implicit memory: Effects of stimulus type, encoding conditions, and number of exposures on recognition and affect judgments. Journal of Experimental Psychology: Learning, Memory, \& Cognition, 21, 711-721.

SEIDENBERG, M. (1987). Sublexical structures in visual word recognition: Access units or orthographic redundancy? In M. Coltheart (Ed.), Attention \& performance XII: The psychology of reading (pp. 245-263). Hillsdale, NJ: Erlbaum.

SPOEHR, K. T., \& SMITH, E. E. (1973). The role of syllables in perceptual processing. Cognitive Psychology, 5, $71-89$.

Stanners, R. F., Neiser, J. J., \& Painton, S. (1979). Memory representation for prefixed words. Journal of Verbal Learning \& Verbal Behavior, 18, 733-743.

TAFT, M., \& FoRSTER, K. I. (1975). Lexical storage and retrieval of prefixed words. Journal of Verbal Learning \& Verbal Behavior, 14, 638647

TAFT, M., \& Forster, K. I. (1976). Lexical storage and retrieval of polymorphemic and polysyllabic words. Journal of Verbal Learning \& Verbal Behavior, 15, 607-620.

Treiman, R. (1986). The division between onsets and rimes in English syllables. Journal of Memory \& Language, 25, 476-491.

Treiman, R., \& Chafetz, J. (1987). Are there onset- and rime-like units in written words? In M. Coltheart (Ed.), Attention and performance XII: The psychology of reading (pp. 281-298). London: Erlbaum.

Tulving, E., \& Schacter, D. L. (1990). Priming and human memory systems. Science, 247, 301-306.

WARRInGton, E. K., \& Shallice, T. (1980). Word-form dyslexia. Brain. 30, 99-112.

WiLliams, P., \& TARR, M. J. (1997). Structural processing and implicit memory for possible and impossible objects. Journal of Experimental Psychology: Learning, Memory, \& Cognition, 23, 1344-1361.

\section{NOTES}

1. In this article, I use the term implicit memory in Schacter's (1987) original sense of the term: to refer to priming effects. I will not be concerned with other forms of implicit memory, such as perceptual, motor, and cognitive skill learning.

2. Two of these studies (Rugg \& Nagy, 1987; Schacter, Rapscak, et al., 1990) involved conditions somewhat different from those of the present experiments. I will examine these differences in further detail in the General Discussion section.

3. An early study by Cermak, Talbot, Chandler, and Wolbarst (1985) failed to observe nonword identification priming in amnesia. Inspection of the data, however, reveals that there was actually a small prim- 
ing effect, which has been replicated subsequently by Cermak and his colleagues (e.g., Cermak et al., 1991).

4. A shallow-processing task was used in the experiments, to minimize the role of explicit memory strategies (see Mandler, Hamson, \& Dorfman, 1990).

5. A scoring scheme based on the proportion of letters correct yielded the same general pattern of results. This was true with both a lenient criterion (the proportion of letters correct in any position) and a strict criterion (the proportion of letters correct in the presented position).

6. This kind of analysis extracts variability due to item and subject differences for different groups used in a counterbalanced design (i.e., it pulls the group $\times$ treatment interaction from the standard error term). Although such an analysis reduces the degrees of freedom as- sociated with a particular effect, the benefits derived from reduced error variability make it a useful application for experiments with within-subjects designs.

7. This is not to deny that material-specific priming effects can occur under certain conditions (see, e.g., findings by Roediger \& Blaxton, 1987, and others). The important point in the present context is that abstract effects also occur and are not readily accounted for in terms of the laying down of new, specific representations.

8 . For interested readers, the $95 \%$ confidence intervals were $(.313$, $.470)$ for morphemic items, $(.049, .519)$ for syllabic items, and $(.042$, .254 ) for pseudosyllabic items.

(Manuscript received March 21, 1996; revision accepted for publication July $18,1997$. 